\title{
Aged Male and Female Spontaneously Hypertensive Rats Benefit from n-3 Polyunsaturated Fatty Acids Supplementation
}

\author{
M. MITAŠÍKOVÁ, S. ŠMIDOVÁ ${ }^{1}$, A. MACSALIOVÁ, V. KNEZL ${ }^{2}$, K. DLUGOŠOVÁ, \\ L. OKRUHLICOVÁ, P. WEISMANN ${ }^{3}$, N. TRIBULOVÁ
}

Institute for Heart Research, Slovak Academy of Sciences, ${ }^{1}$ Faculty of Life Sciences, Comenius University, ${ }^{2}$ Institute of Experimental Pharmacology, Slovak Academy of Sciences, ${ }^{3}$ Medical Faculty, Comenius University, Bratislava, Slovak Republic

Received January 25, 2008

Accepted March 25, 2008

On-line March 28, 2008

\begin{abstract}
Summary
Hypertension-induced myocardial metabolic, structural and electrophysiological remodeling deteriorates with aging and contributes to both heart failure and occurrence of malignant arrhythmias. It has been shown in clinical trials that $n-3$ polyunsaturated fatty acids ( $n-3$ PUFA) reduce the incidence of cardiovascular diseases and sudden cardiac death. We investigated the cardioprotective effects of n-3 PUFA in aged spontaneously hypertensive rats (SHR) and possible cellular mechanisms involved. Male and female 14-moth-old SHR were fed with n-3 PUFA (Vesteralens, Norway, $20 \mathrm{mg} /$ day for two months) and compared with untreated SHR. Results showed that n-3 PUFA supplementation led to 1) significant decline of blood pressure; 2) suppression of inducible ventricular fibrillation (VF) by $57 \%$ (male) and $67 \%$ (female), although the arrhythmogenic substrates, like fibrosis, hypertrophy and abnormal gap junctions distribution were not eliminated; 3) preservation of the cardiomyocytes and the integrity of their junctions; 4) enhancement of energetic metabolism enzyme activity; 5) augmentation of capillary density associated with increased alkaline phosphatase and decreased dipeptidyl peptidase-4 (DPP4) activity and 6/ increase in gap junction channel connexin43 expression. Thus, aged male as well as female SHR benefit from n-3 PUFA supplementation that results in decrease in VF susceptibility, partly due to an improvement of myocardial metabolic state, cardiomyocyte and cell-to-cell junctions integrity and $\mathrm{Cx} 43$ up-regulation.
\end{abstract}

\section{Key words}

SHR, n-3 PUFA • Ventricular fibrillation • Connexin-43 •

Myocardial enzymes $\bullet$ DPP4 $\bullet$ Ultrastructure

\section{Corresponding author}

Narcis Tribulová, Institute for Heart Research, Slovak Academy of Sciences, 84005 Bratislava, Dúbravská cesta 9, P.O. Box 104, Slovak Republic. Fax:+421 $254776637 . \quad$ E-mail: narcisa.tribulova@savba.sk

\section{Introduction}

Increased consumption of fish oil, rich in n-3 polyunsaturated fatty acids (n-3 PUFA), has been shown in numerous epidemiological studies and clinical trials to reduce the incidence of cardiovascular disease (Balk et al. 2006, Saks and Katan 2002), atrial fibrillation (Mazgalev 2005) and sudden cardiac death (SCD) presumably by preventing life threatening arrhythmias (Leaf et al. 2003, Lee and Lip 2003). Based on the scientific evidence numerous cardiac societies (The American Heart Association, The European Society for Cardiology and national cardiac societies) recommend the daily intake of $1 \mathrm{~g}$ of the two n-3 (omega-3) fatty acids, eicosapentaenoic acid (EPA) and docosahexaenoic acid (DHA), for primary and secondary cardiovascular disease prevention, treatment of post-myocardial infarction and prevention of SCD (von Schacky and Harris 2007). Beneficial physiologic effects of n-3 PUFA include inhibition of prostacycline, thromboxane and cytokine production to reduce inflammation, reduction of endothelial adhesion molecule expression, reduction of vasospastic response to catecholamines, reduction of blood viscosity, decreased levels of platelet-activating factor and platelet-derived growth factor and decreased oxygen free-radical generation (Leaf and Weber 1988).

Antiarrhythmic properties of n-3 PUFA have been reported in animal models as well (Billman et al. 1999, Leaf et al. 2003). Several mechanisms have been proposed and studied to explain anti-arrhythmic actions of n-3 PUFA, but no definite mechanism has been 
validated. Nevertheless, the effects of n-3 PUFA on variety of cardiac ion channels and exchangers (Leaf et al. 2003, Den Ruijter et al. 2007) likely resulting in alterations of cardiac electrophysiology in humans (Mozaffarian et al. 2006) can play a role. In addition, n-3 PUFA alter the antioxidant status of cardiac cells (Jahangiri et al. 2006), modulate $\mathrm{Ca}^{2+}$ handling (Kinoshita et al. 1994, Leaf et al. 2003) and sarcoplasmic reticulum function (Honen et al. 2003) as well as prevent asynchronous contractility (Leifert et al. 2001). However, the data whether n-3 PUFA supplementation affects gap junction connexin-43 (Cx43) channels, which ensure cardiac cell-to-cell coupling for electrical signal propagation and myocardial synchronization, are missing.

The majority of clinical data deals with beneficial effects of n-3 PUFA in coronary heart diseases and prevention of malignant arrhythmias in the setting of myocardial ischemia and/or reperfusion (Sacks and Katan 2002, von Schacky and Harris 2007, Lee and Lip 2003). However, hypertension results also in functional as well as arrhythmic complications known in both experimental and clinical conditions (Bing et al. 1995, Kostin et al 2004, Tribulová et al. 2002a). It is likely due to hypertension-induced myocardial abnormalities including structural and gap junction remodeling that deteriorates with aging and/or disease progression (Fialová et al. 2008, Kostin et al. 2004, Teunissen et al. 2004, Tribulová et al. 2002b, 2003). Interestingly, gender-related differences in structural remodeling were reported during disease progression to heart failure (Tamura et al. 1999). As well as the extrusion of excessive $\mathrm{Na}^{+}$out from the cardiac cells is adapted better to hypertension in female hearts, as suggested by improved activity of the cardiac sodium pump in female SHR (Vlkovičová et al. 2005). Thus, long-term hypertension, similarly as ischemic heart disease, result in increased risk of SCD.

It is therefore of interest to know whether n-3 PUFA supplementation can affect susceptibility of aged male and female SHR hearts to ventricular fibrillation (VF), gap junction $\mathrm{Cx} 43$ distribution and expression, extracellular matrix and cardiomyocyte structure, as well as activity of selected enzymes that ensure energy production and capillary functions.

\section{Methods}

All animal experiments were performed in accordance with the rules issued by the State Veterinary Administration of the Slovak Republic, legislation No
289/2003 and with the regulations of the Animal Research and Care Committee of Institute for Heart Research. Experiments were conducted using spontaneously hypertensive rats (SHR), a model that mimics human essential hypertension and is suitable to monitor myocardial changes during transition from compensated left ventricular hypertrophy to heart failure in aging ( $>1$ year-old) rats (Bing et al. 1995). Male and female 14 month-old SHR ( $n=24)$ were fed with $n-3$ PUFA (Vesteralens, Norway, $20 \mathrm{mg}$ /day) for two months and compared with SHR $(n=24)$ fed on standard laboratory chow. At the end of the experiments body weight (BW) was registered and the blood pressure (BP) was measured by tail-cuff plethysmography using the Statham Pressure Transducer P23XL (Hugo Sachs, Germany).

The hearts of six rats from each group (rapidly excised under ether anesthesia) were perfused via canulated aorta in Langendorff mode with oxygenated Krebs-Henseleit solution at constant pressure and temperature of $37{ }^{\circ} \mathrm{C}$. Bipolar ECG, the left ventricular pressure and the coronary flow were continuously monitored. Upon 20 min of equilibration, VF inducibility was tested using a 1-sec burst of electrical rectangular pulses, $100 \mathrm{pps}$, duration $1 \mathrm{~ms}$ and $1.5 \mathrm{x}$ threshold voltage (Electrostimulator ST-3“, Hungary) delivered via stimulating electrodes attached to the epicardium of the right ventricle. Repetitive stimulation was performed during 5 min period unless sustained VF occurred earlier.

The hearts of other six rats from each group were rapidly frozen in liquid nitrogen for preparing ventricular cryostat sections. These were used for enzyme histochemistry and for in situ immunodetection of major myocardial gap junction channel protein $\mathrm{Cx} 43$ using mouse monoclonal antiCx43 antibody (Chemicon) and FITC conjugated goat anti-mouse antibody (Tribulová et al. 2002a, 2003). Accordingly, myocardial energetic metabolism was monitored by histochemically (in situ) determined activities of glycogen phosphorylase (E.C.2.4.1.18), mitochondrial succinate (E.C.1.3.99.1) and $\beta$-hydroxybutyrate dehydrogenases (1.1.1.30) and cell membrane 5'-nucleotidase (E.C.3.1.3.5). Capillary endothelium-related alkaline phosphatase (E.C.3.1.3.1) and dipeptidyl peptidase-4 (DPP4, E.C.3.4.15.4) activities were used to detect myocardial capillary network and capillary endothelium functions (Lojda et al. 1976).

Transmural cryostat sections of the ventricles underwent formaldehyde postfixation followed by 
Table 1. Hemodynamic parameters of Langendorff-perfused heart isolated from untreated and $n-3$ PUFA-treated male $(m)$ and female (f) SHR.

\begin{tabular}{lcccc}
\hline & SHR-m & SHR-m + PUFA & SHR-f & SHR-f + PUFA \\
\hline HR (beats $/ \mathrm{min})$ & $204.43 \pm 6.23$ & $246.64 \pm 14.65^{*}$ & $220.93 \pm 5.23$ & $193.80 \pm 14.76$ \\
$C F(\mathrm{ml} / \mathrm{min})$ & $15.60 \pm 1.96$ & $14.54 \pm 0.50$ & $8.86 \pm 0.42$ & $10.60 \pm 0.20^{*}$ \\
$R P P$ & $18533 \pm 2371$ & $22820 \pm 1703^{*}$ & $17490 \pm 760$ & $17170 \pm 1074$ \\
\hline
\end{tabular}

HR - heart rate; CF - coronary flow; RPP - rate pressure product; $* \mathrm{P}<0.05$ treated vs. untreated

Table 2. Semiquantitative evaluation of histochemical and subcellular myocardial alterations in male (m) and female (f) $n-3$ PUFA treated and untreated SHR

\begin{tabular}{lcccc}
\hline & SHR-m & SHR-m + PUFA & SHR-f & SHR-f + PUFA \\
\hline Histochemistry & & & & \\
GlyP & 1,2 & 2,3 & 1,2 & 2,3 \\
SDH & $1,2,3$ & 2,3 & $1,2,3$ & 2,3 \\
$\beta-H B D H$ & 1,2 & 2,3 & 1,2 & 2,3 \\
' $^{N C}$ & 1,2 & 2,3 & 1,2 & 2,3 \\
Electron microscopy & & & & \\
Sarcolemma & $\mathrm{N}, \mathrm{M}, \mathrm{S}$ & $\mathrm{N}, \mathrm{M}$ & $\mathrm{N}, \mathrm{M}, \mathrm{S}$ & $\mathrm{N}, \mathrm{M}$ \\
Mitochondria & $\mathrm{N}, \mathrm{M}, \mathrm{S}$ & $\mathrm{N}, \mathrm{M}$ & $\mathrm{N}, \mathrm{M}, \mathrm{S}$ & $\mathrm{N}, \mathrm{M}$ \\
Junctions & $\mathrm{N}, \mathrm{M}, \mathrm{S}$ & $\mathrm{N}, \mathrm{M}$ & $\mathrm{N}, \mathrm{M}, \mathrm{S}$ & $\mathrm{N}, \mathrm{M}$ \\
\hline
\end{tabular}

Scores indicate intensity of histochemical reaction corresponding to enzyme activity: 1 - weak; 2 - moderate; 3 - strong. More numbers indicate ventricular tissue heterogeneity in selected enzyme activity that is well demonstrated in Fig. 6 . GlyP - glycogen phosphorylase; $\mathrm{SDH}$ - succinic dehydrogenase; $\beta$ - $\mathrm{HBDH}$ - $\beta$-hydroxybutyrate dehydrogenase; $5^{\prime} \mathrm{NC}-5^{\prime}$-nucleotidase. Scores for subcellular alterations: $\mathrm{N}$ - normal appearance; $\mathrm{M}$ - moderate alterations; $\mathrm{S}$ - severe alterations. Note myocardial heterogeneity of subcellular alterations/injury of the cardiomyocytes.

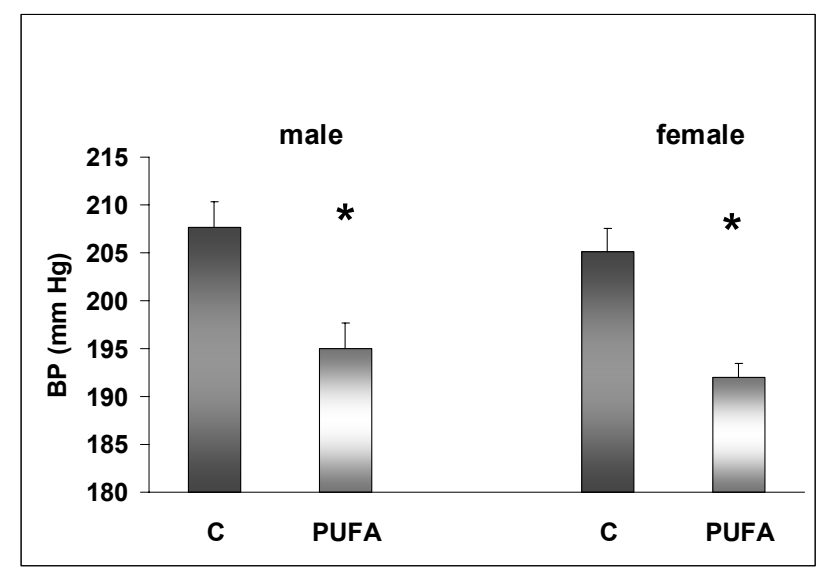

Fig. 1. Systolic blood pressure in aged male and female SHR without and with $\mathrm{n}-3$ PUFA supplementation. ${ }^{*} \mathrm{P}<0.05$ treated vs. untreated SHR

histological Van Gieson staining to recognize fibrosis. Small $(1-2 \mathrm{~mm})$ ventricular heart tissue samples taken from epi- and endocardial layers ( $\mathrm{n}=8$ per each group) were fixed in buffered $2.5 \%$ glutaraldehyde and routinely processed for transmission electron microscopy (Tribulová et al. 2003). Subcellular alterations, i.e. injury of the sarcolemma, mitochondria and intercellular junctions integrity were semiquantitatively evaluated using 10 pictures per heart. Myocardial immunodetection of $\mathrm{Cx} 43$ and enzyme histochemistry were examined using light and fluorescence microscope Axiostar (Carl Zeiss Jena, Germany) and digitized pictures were collected into $\mathrm{PC}$ for consequent semiquantitative and quantitative image analysis (GmBh Soft Imaging System, Germany).

\section{Statistical analysis}

All results are presented as mean \pm SEM. The significance of difference between untreated and treated groups was statistically evaluated using one-way ANOVA and Student t-test. Values were considered to differ significantly when $\mathrm{P}<0.05$. 


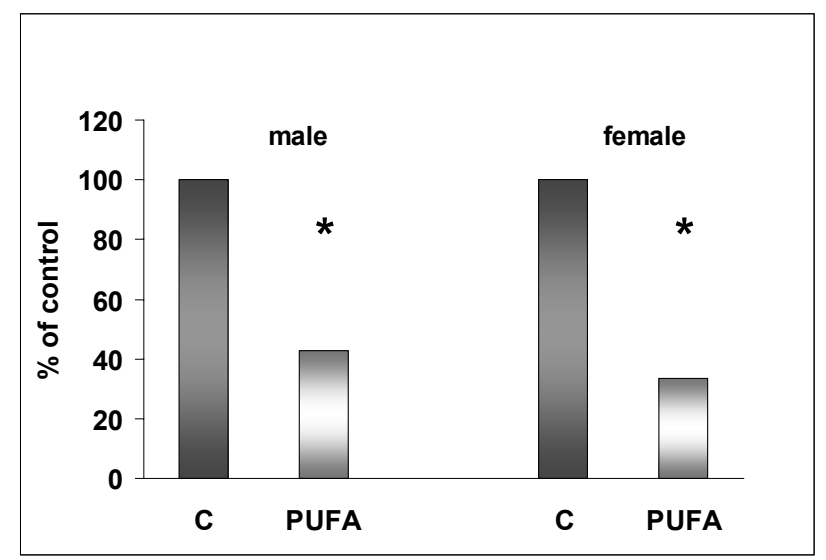

Fig. 2. Incidence of inducible sustained ventricular fibrillation in isolated perfused heart of aged male and female untreated and n-3 PUFA-treated SHR. * $\mathrm{P}<0.05$ treated vs. untreated.

\section{Results}

The supplementation with n-3 PUFA resulted in blood pressure reduction in both male and female SHR (Fig. 1), while body weights were not affected (342 \pm 3 vs. $330 \pm 5 \mathrm{~g}$ in male and $210 \pm 10 \mathrm{~g}$ vs. $215 \pm 3 \mathrm{~g}$ in female rats). Heart rate monitored in isolated Langendorffperfused heart was significantly decreased in female, but increased in male n-3 PUFA-treated SHR, which also exhibited augmented rate pressure product. The latter is an indicator of cardiac output. Coronary flow was significantly increased in female while not changed in male n-3 PUFA-treated SHR (Table 1).

All untreated SHR hearts were susceptible to electrically-induced sustained VF, whereby males developed VF sooner, i.e. upon the first or after a few stimuli. In contrast, inducible VF was significantly suppressed by $57 \%$ and $67 \%$ in PUFA-treated male and female SHR (Fig. 2). Noteworthy, n-3 PUFA supplementation led to clear anti-fibrillating effects, although a myocardial remodeling, i.e. fibrosis and hypertrophy-induced gap junction $\mathrm{Cx} 43$ remodeling ("lateralization") was not eliminated (Fig. 3). Thus, immunolabeling of myocardial $\mathrm{Cx} 43$ showed end-to-end type (intercalated disc-related) and enhanced expressionof side-to-side type of gap junctions (Fig. 3) in the ventricles of SHR regardless the treatment. Quantitative image analysis of Cx43 expression (Fig. 4) revealed a marked increase in immunofluorescence signal in n-3 PUFA-treated male and female rats. It did not reach, however, statistical significance when compared to untreated rats likely due to individual variability caused by diffuse fibrosis that was not eliminated by the n-3
PUFA treatment. Noteworthy, expression of $\mathrm{Cx} 43$ was significantly higher in female compared to male untreated SHR.

Furthermore, n-3 PUFA supplementation resulted in better preservation of ultrastructure of the cardiomyocytes and their junctions in both males and females SHR hearts (Fig. 5, Table 2). In situ catalytic enzyme histochemistry (Fig. 6, Table 2) pointed out an increase of glycogen phosphorylase, mitochondrial succinate and $\beta$-hydroxybutyrate dehydrogenase activity as well as that of cell membrane 5'-nucleotidase. In addition, n-3 PUFA supplementation led to an increase in capillary density and related alkaline phosphatase activity in the ventricles of n-3 PUFA treated male and female rats. The increase was more pronounced in males, which without treatment exhibited lower enzyme activity compared to female. On the contrary, activity of capillary-related DPP4 was significantly decreased due to n-3 PUFA in both sexes, as shown by quantitative image analysis, (Figs. 7A, 7B). The decrease was more pronounced in females SHR, which without treatment exhibited higher enzyme activity compared to male.

\section{Discussion}

Prevention of ventricular arrhythmias by $n-3$ PUFA is well documented in clinical as well as animal experimental studies in the setting of ischemia or postinfarction. Our study showed, for the first time, the antifibrillating effects of n-3 PUFA in rats suffering from spontaneous (essential) hypertension. During aging, the heart failure develops in these rats due to changes of intrinsic properties of the myocardium and due to connective tissue alterations (Bing et al. 1995). In agreement with it, the profound replacement and perivascular fibrosis as well as subcellular alterations of the cardiomyocytes and their junctions in the left ventricles of aged male and female SHR suggest deteriorated heart function. In this context it should be stressed that anti-fibrillating effects of n-3 PUFA occurred despite the presence of pronounced myocardial structural remodeling. The latter is thought to be highly arrhythmogenic because it includes gap junctions remodeling characterized by changes in topology of gap junctions due to their lateralization and internalization (Fialová et al. 2008, Kostin et al. 2004, Saffitz et al. 1999, Teunissen et al. 2004, Tribulová et al. 2002b). Since we detected disordered distribution of gap junctionrelated connexin channels it can results in conduction 

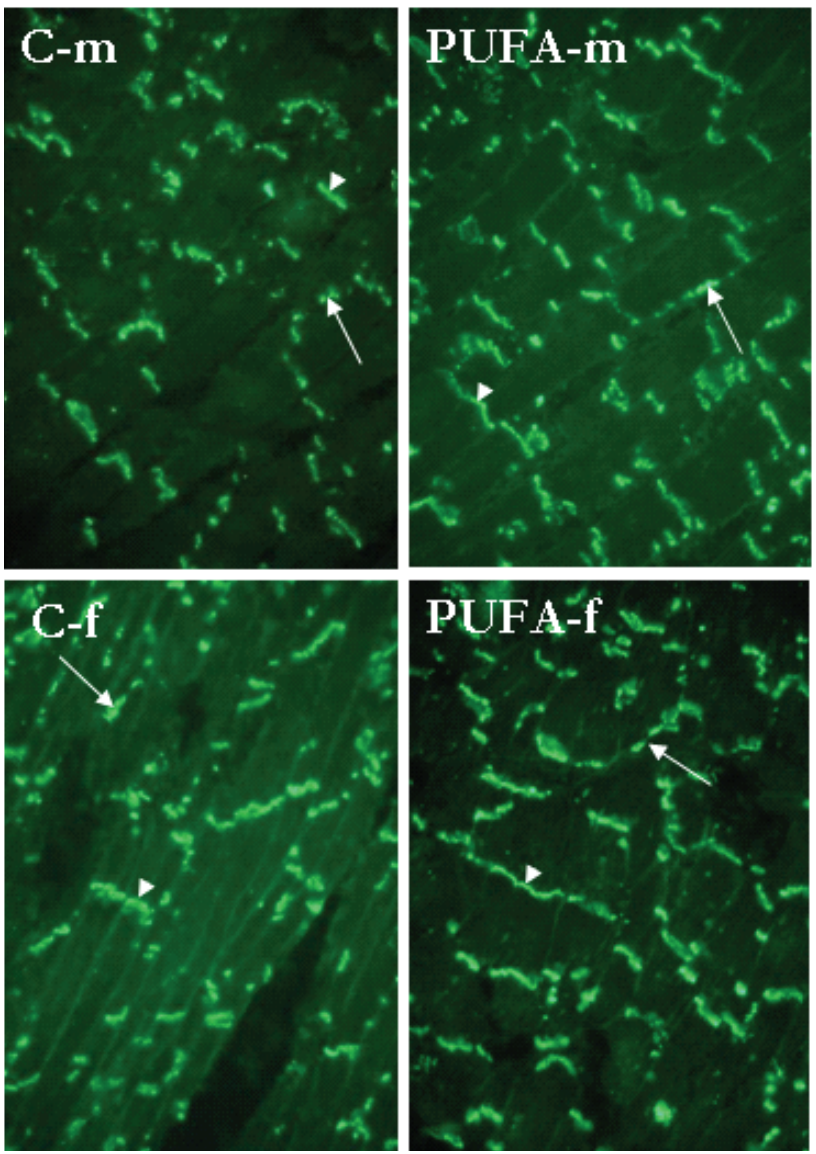

disturbances and contributes to myocardial electrical instability that consequently promotes occurrence of reentrant arrhythmias (Saffitz et al 1999, Spach and Heidlage 1995). These life-threatening arrhythmias are most often triggered by acute pathophysiological events that induce gap junctional uncoupling as suggested by experimental studies (De Groot and Coronel 2004, Tribulová et al. 2002a, 2003) and by clinical reports. Moreover, left ventricular hypertrophy itself can trigger arrhythmias due to ectopic impulse generation (Tribulová et al. 2003). We have used an electrical stimulation of isolated perfused heart to test VF inducibility, similarly as is a programmed electrical stimulation used in clinic (in order to evaluate the propensity to develop VF in the high-risk patients).

Compared to non-hypertensive rats, $\mathrm{Cx} 43$ expression and/or phosphorylation have been shown to be significantly decreased in either hypertrophied hearts of SHR (Tribulová et al 2002a, 2003) or humans with decompensated cardiac hypertrophy (Kostin et al. 2004). Defects in Cx43 expression, particularly when heterogeneously distributed throughout myocardium, render the heart prone to $\mathrm{VF}$, as was confirmed also by this study. In contrast, we have shown that an apparent

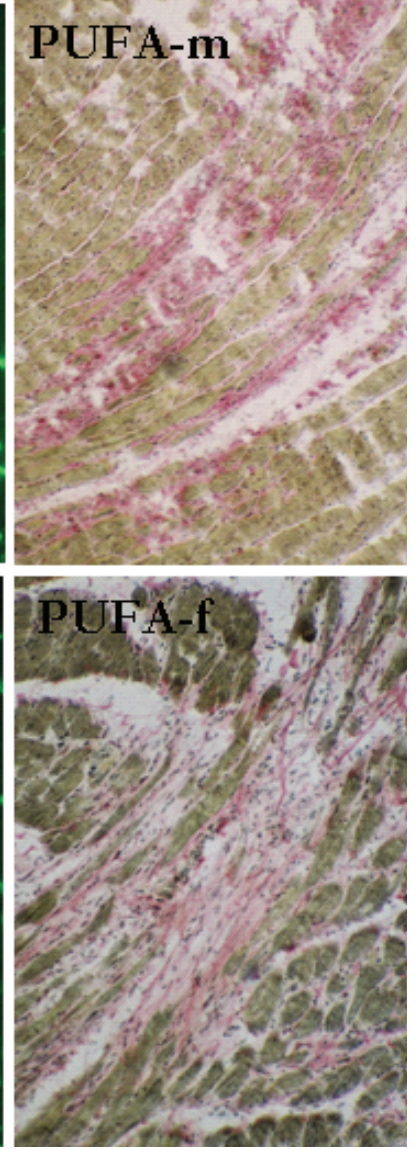

Fig. 3. Immunolabeling of connexin-43 positive gap junctions and Van Gieson staining of fibrotic areas (pink color) in aged male $(\mathrm{m})$ and female (f) SHR heart ventricle. $\mathrm{C}-\mathrm{m}$ and $\mathrm{C}-\mathrm{f}-\mathrm{untreated}$ SHR; PUFA-m and PUFA- $f-n-3$ PUFA-treated SHR. Note end-toend type of intercalated discrelated and side-to-side type of lateral gap junctions. Magnification $80 \mathrm{x}$.

increase in $\mathrm{Cx} 43$ immunolabeling found in both male and female n-3 PUFA- treated SHR (Fig. 4) was associated with suppression of VF inducibility. An increase of Cx43, however, did not reach statistically significant values, likely due to individual variations caused by patchy areas of replacement fibrosis. Noteworthy, the Cx43 immunosignal was significantly lower in male compared to female SHR pointing out gender-related differences that can be implicated in distinct VF susceptibility. Indeed, sustained VF was induced upon first or after a few stimuli in males, while only after numerous repetitive stimuli in untreated female SHR. It appears that the level of the Cx43 expression, either intrinsic or induced by diet-therapy (n-3 PUFA), is implicated in the arrhythmia susceptibility. Further analysis is necessary to learn to which extent n-3 PUFA can modulate expression and/or phosphorylation and gene transcription of $\mathrm{Cx} 43$ and particularly Cx43 channel conduction.

Cx43 is a highly dynamic trans-membrane protein and active signaling molecule crucial for the synchronous cardiac function. We hypothesize that $\mathrm{Cx} 43$ channel properties determining its conduction (e.g. phosphorylation state or allosteric conformation) may be altered due to incorporation of n-3 PUFA into cardiac 


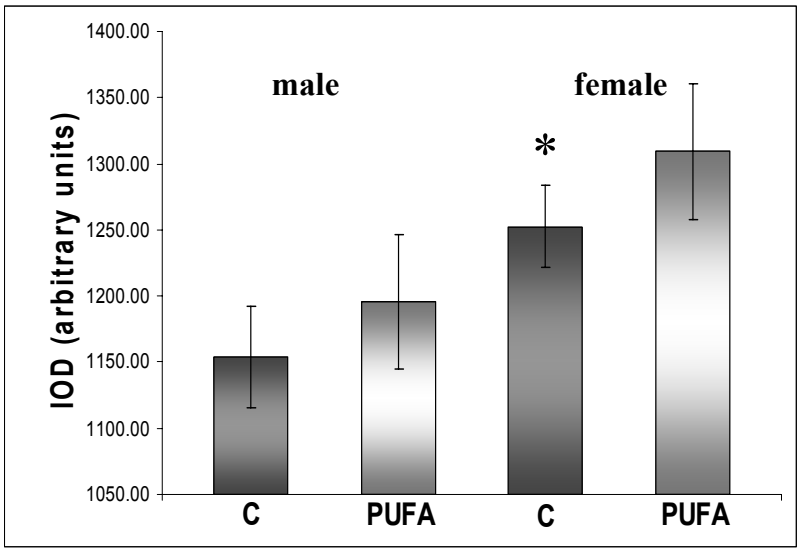

Fig. 4. Quantitative image analysis of connexin-43 expression in aged male and female untreated (C) and n-3 PUFA-treated SHR. IOD - intensity of immunofluorescence signal per area. $* \mathrm{P}<0.05$ untreated female vs. untreated male.

phospholipid cell membrane. Indeed, n-3 PUFA (i.e. EPA and DHA) form a part of cell membrane, replacing other mostly unsaturated fatty acids upon incorporation, and thereby modulating membrane fluidity and cellular functions (Harris 2007, von Schacky and Harris 2007). DHA enrichment of membrane phospholipids was shown to increase gap junction coupling capacity in cultured astrocytes (Champeil-Potokar et al. 2006). It seems therefore very likely that incorporated n-3 PUFA can modulate $\mathrm{Cx} 43$ channel (as well as other channel) function (Den Ruijter et al. 2001), perhaps via affecting microdomains of cell membrane trough which the channel protein penetrates (Leaf et al. 2003). Preservation of cell-to-cell junctions, sarcolemma and cardiomyocyte integrity in aged male and female SHR hearts can be, in part, explained by n-3 PUFA-related modulation of membrane composition. Thus, incorporated n-3 PUFA in our experiments may also stabilize cardiomyocyte membranes and by this way affect electrical excitability and VF vulnerability (Lee and Lip 2003, Leaf et al. 2003, Siskovick et al. 2003). It seems that n-3 PUFA can suppress in hypertrophied heart both re-entrant lethal arrhythmias and ventricular premature contractions triggered by ectopic activity. Some reports, however, suggest that antiarrhythmic effects of n-3 PUFA depend rather on their free circulating levels (Dhein et al. 2005, Leaf et al. 2003). Further studies are thus needed to elucidate this vital issue.

A number of plausible mechanisms have been proposed to explain the cardioprotective and/or antiarrhythmic effects attributed to n-3 PUFA, i.e. structural and electrophysiological as well as metabolic and autonomic ones (Reiffel and McDonald 2006). We
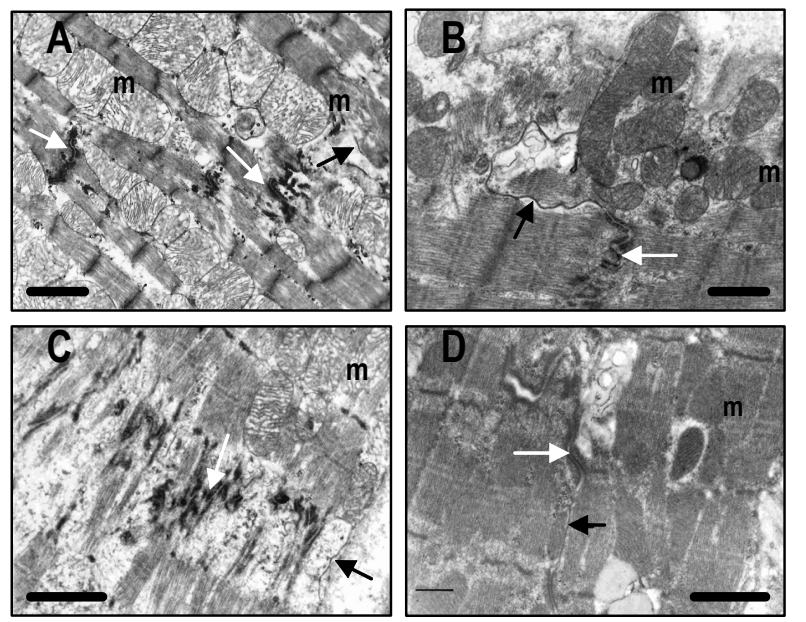

Fig. 5. Representative electron microscopic pictures showing impaired mitochondria $(\mathrm{m})$ and cardiomyocyte junctions integrity in untreated aged SHR (A-male, C- female) and preservation of ultrastructure in n-3 PUFA-treated male (B) and female (D) SHR. White arrows - adhesive fascia adherens junctions that ensure contractile force propagation; black arrows - gap junctions that ensure electrical coupling among cardiomyocytes; bar $-1 \mu \mathrm{m}$.

have shown that n-3 PUFA decreased significantly blood pressure not only in male and female SHR but also in hypertriglyceridemic rats (a rat model of metabolic disease accompanied by mild hypertension) (Zicha et al. 2006), in which in addition decreased plasma triglyceride levels (Tribulová et al. 2007). It is in accordance with the findings that $\mathrm{n}-3$ PUFA supplementation influence lipid metabolism (Davidson et al. 2006) and it was also indicated in this study by increase of myocardial $\beta$-hydroxybutyrate dehydrogenase activity. While the enhancement of succinate dehydrogenase, glycogen phosphorylase and 5'-nucleotidase activity points out an improvement of energetic and nucleoside metabolism in aging SHR hearts. Augmented production of adenosine can play a role in suppression of arrhythmogenic effects of elevated catecholamines (e.g. in the setting of acute ischemia, stress conditions, including repetitive electrical stimulation) or in improvement of coronary blood flow. The latter was significantly increased in female $n-3$ PUFA-treated SHR. Metabolic protection that was apparent in our study can be possible via activation of peroxisome proliferator-activated receptors (PPARs) linked with modulation of gene expression (Davidson 2006). The PPAR family of nuclear receptors regulates many genes involved in cardiac energy metabolism. Ligands for PPARs including n-3 PUFA induce several genes encoding proteins involved in lipid and glucose metabolism, while they down-regulate genes related to cardiac remodeling, apoptosis or inflammation (Bordoni 

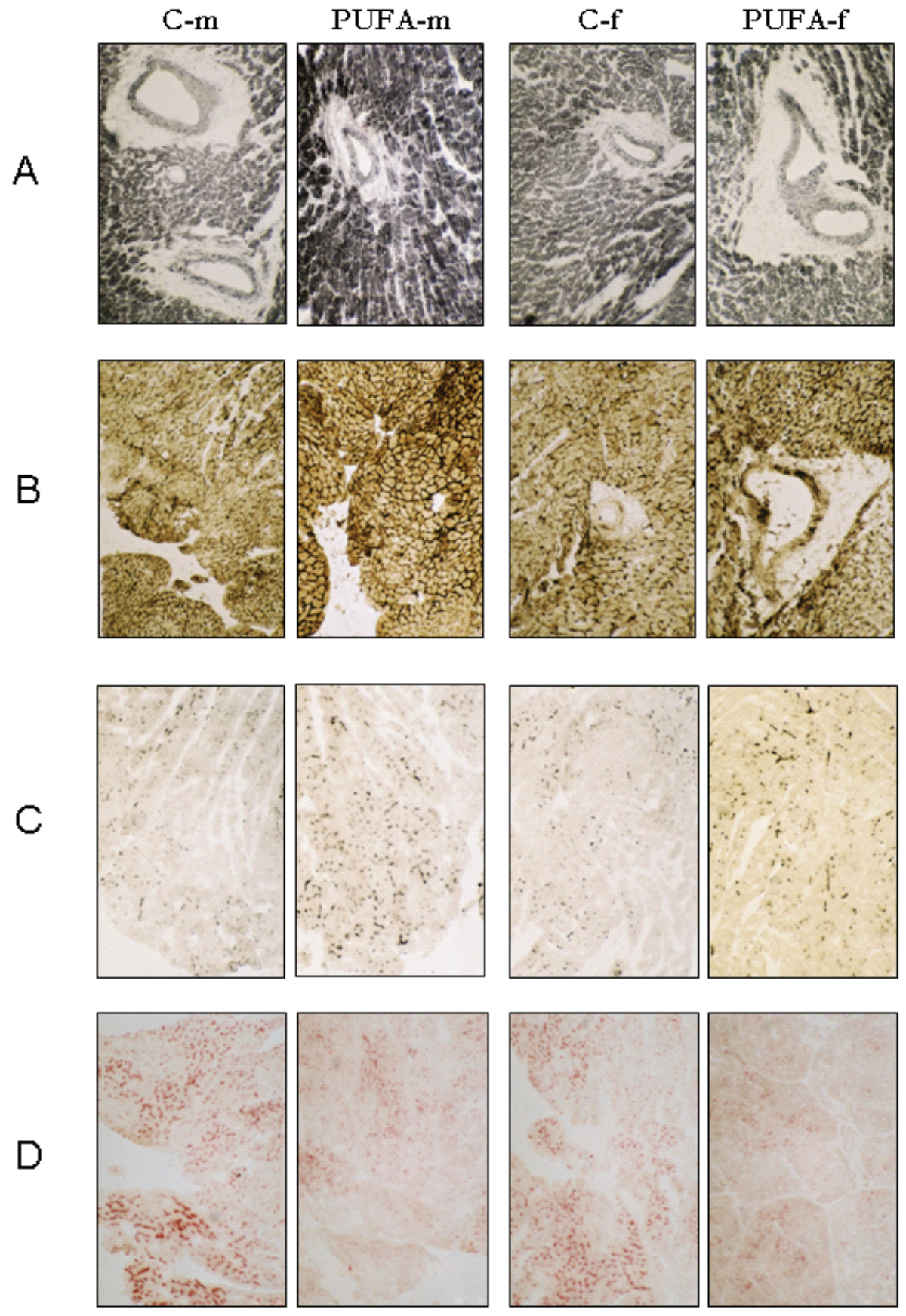

Fig. 6. Catalytic enzyme histochemistry performed on cryostat sections of ventricular tissue from aged male (C-m) and female (C-f) control and n-3 PUFA-treated SHR. Alkaline phosphatase (C) and DPP4 activity. Note spatial heterogeneity in enzyme activity that is more pronounced in untreated SHR. There is an increase of myocardial $\beta$-hydroxy-butyrate dehydrogenase (A), $5^{\prime}$-nucleotidase (B) and capillary-related alkaline phosphatase activity, while capillary DPP4 was decreased due to n-3 PUFA diet-therapy. Magnification 80 x.

et al. 2007). These data thus suggest that the mechanisms of cardioprotective and antiarrhythmic actions of n-3 PUFA can be related to direct effects on cardiac cell genome.

Our results showed also for the first time that n-3 PUFA can affect capillary endothelium functions, as indicated by a significant increase of alkaline phosphatase (AlP) and a suppression of DPP4 activity. The former is a marker of the arterial while the latter of the venous part of the myocardial capillary network (Lojda 1979). AlP is responsible for break-down of phosphate esters and its most important function is the phosphate transfer. Its activity is very high in cell membranes with high transport functions, such as capillary endothelium. Untreated SHR exhibited decrease in capillary AlP and increase in DPP4 activity that can reflect maladaptation of the heart to stress conditions (Koyama et al. 1998), while n-3 PUFA attenuated this process. In this context, 


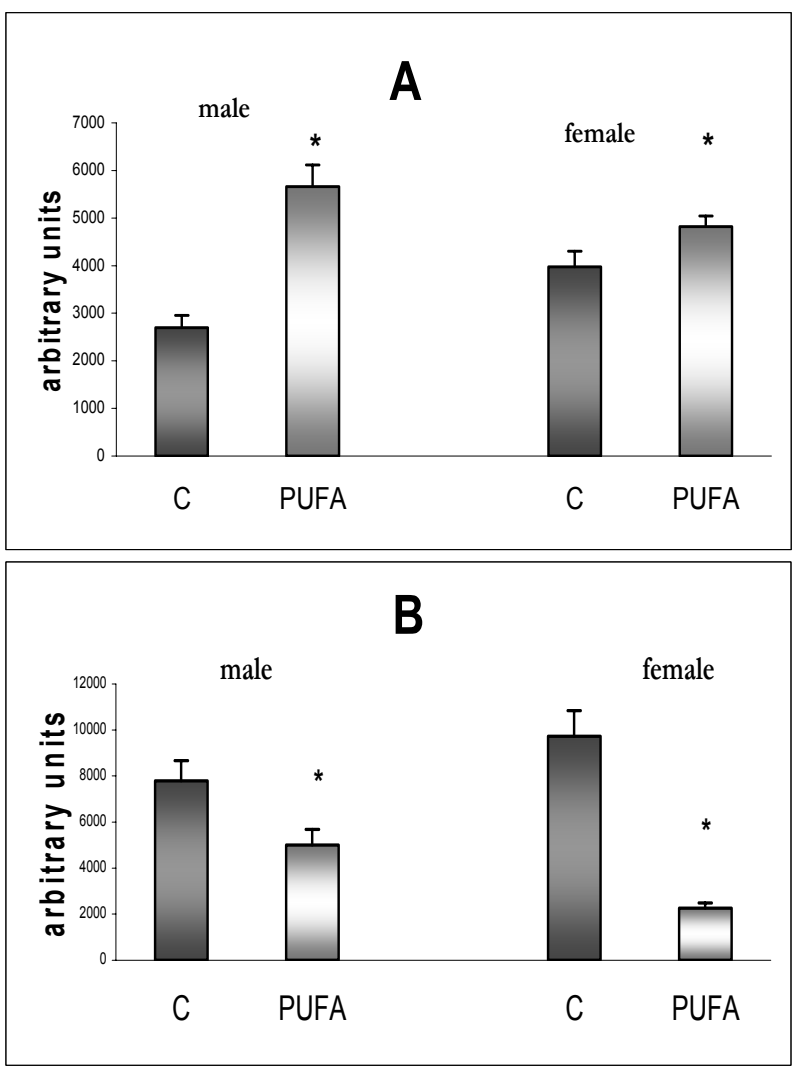

Fig 7. Quantitative image analysis of alkaline phosphatase ( $A$, a marker of arterial part of capillary network) and DPP4 (B, a marker of venous part of capillary network) activity in the left ventricle of aged male and female untreated (C) and n-3 PUFA treated SHR hearts. ${ }^{*} \mathrm{P}<0.05$ treated vs untreated SHR.

our results suggest clear sex-related differences (shown in Fig.7). High molecular substances escape from the capillary bed preferentially in the venous part endowed by DPP4. This enzyme (which also exists in soluble form in plasma) breaks down many chemokines, neuropeptides, vasoactive peptides and hormones present in circulation, which suggests its role in the regulation of various physiological processes, including glucose homeostasis (Lambeir et al. 2003). It has been shown that DPP4 rapidly cleaves B-type natriuretic peptide, BNP 1-32 (which play an important role in cardio-renal homeostasis and its expression is up-regulated in cardiac overload) to BNP 3-32 that was associated with reduced natriuresis and lack of vasodilating actions (Boerigter et al. 2007). Moreover, DPP4 has been implicated in the collagen metabolism and synthesis of the endothelial coat, which is important for the binding of glycosaminoglycans (Lojda 1979). DPP4 activity was increased in human fibrotic atria exhibiting persistent atrial fibrillation (Lendeckel et al. 2001). Taken together, all these data imply that suppression of DPP4 activity by n-3 PUFA can be beneficial for aged hypertensive rat heart. In view of the recent data, the DPP4 activity has been proposed as a diagnostic or prognostic marker for various human disorders. Furthermore, DPP4 inhibitors improve glucose tolerance (via prevention of cleaving peptide hormones involved in insulin secretion) and are potent drugs for treatment of type 2 diabetes (Lambeir et al. 2003). The latter when accompanied with hypertension contributes to the development of disease known as metabolic syndrome. It can be expected that n-3 PUFA diet-therapy can prevent or attenuate this metabolic disease, whose incidence is increasing in our population.

In conclusion, male as well as female spontaneously hypertensive rats benefit to similar extent from n-3 PUFA supplementation particularly due to suppression of life-threatening arrhythmias. Nevertheless, there is a need to continue in both clinical and experimental studies that will explore the mechanisms through which n-3 PUFA decrease the risk of sudden cardiac death presumably caused by ventricular fibrillation.

\section{Conflict of Interest}

There is no conflict of interest.

\section{Acknowledgements}

This study was realized by support of APVV 51-059505 and VEGA 6064/26, 2/5021/26, 2/7094/27 grants. n-3 PUFA were generous gift of Vesteralens Company, Norway.

\section{References}

BALK EM, LICHTENSTEIN AH, CHUNG M, KUPELNICEK B, CHEW P, LAU J: Effects of omega-3 fatty acids on serum markers of cardiovascular disease risk. Atherosclerosis 189: 19-30, 2006.

BILLMAN GE, KANG JX, LEAF A: Prevention of sudden cardiac death by dietary pure omega-3 polyunsaturated fatty acids in dogs. Circ 99: 2452-2457, 1999. 
BING OHL, BROOKS WW, ROBINSON KG, SLAWSKY MT, HAYES JA, LITWIN SE, SEN S, CONRAD CH: The spontaneously hypertensive rat as a model of the transition from compensated left ventricular hypertrophy to failure. J Mol Cell Cardiol 27: 383-396, 1995.

BOERRIGTER G, COSTELLO-BOERRIGTER LC, HARTY GJ, LAPP H, BURNETT JC: Des-serine-proline brain natriuretic peptide 3-32 in cardiorenal regulation. Am J Physiol 292: R897-R901, 2007.

BORDONI A, ASTOLFI A, MORANDI L, PESSION A, DANESI F, DI NUNZIO M, FRANZONI M, BIAGI PL, PESION A: N-3 PUFAs modulate global gene expression profile in cultured rat cardiomyocytes. Implication in cardiac hypertrophy and heart failure. FEBS Letters 581: 923-929, 2007.

CHAMPEIL-POTOKAR G, CHAUMONTET C, GUESNET P, LAVIALLE M, DENIS I: Docosahexaenoic acid (22:6n-3) enrichment of membrane phospholipids increases gap junction coupling capacity in cultured astrocytes. Eur J Neurosci 24: 3084-3090, 2006.

DAVIDSON MH: Mechanisms for the hypotriglyceridemic effect of marine omega-3 fatty acids. Am J Cardiol 98: 27i-33i, 2006.

DE GROOT JR, CORONEL R: Acute ischemia-induced gap junctional uncoupling and arrhythmogenesis. Cardiovasc Res 62: 323-334, 2004.

DEN RUIJTER HM, BERECKI G, OPTHOF T, VERKERK AO, ZOCK PL, CORONEL R: Pro- and antiarrhytmic properties of a diet rich in fish oil. Cardiovasc Res 73: 316-325, 2007.

DHEIN S, MICHAELIS B, MOHR FW: Antiarrhythmic and electrophysiological effect of long-chain $\omega-3$ polyunsaturated fatty acids. Naunyn-Schmiedeberg's Arch Pharmacol 371: 202-211, 2005.

FIALOVÁ M, DLUGOŠOVÁ K, OKRUHLICOVÁ L', KRISTEK F, MANOACH M, TRIBULOVÁ N: Adaptation of the heart to hypertension is associated with maladaptive gap junction connexin-43 remodeling. Physiol Res 57: 7-11, 2008.

HARRIS WS: Omega-3 fatty acids and cardiovascular disease: a case for omega-3 index as a new risk factor. Pharmacol Res 55: 217-223, 2007.

HONEN BN, SAINT DA, LAVER DR: Suppression of calcium sparks in rat ventricular myocytes and direct inhibition of sheep cardiac RyR channels by EPA, DHA and oleic acid. J Membr Biol 196: 95-103, 2003.

JAHANGIRI A, LEIFERT WR, KIND KL, MC MURCHIE EJ: Dietary fish oil alters cardiomyocyte $\mathrm{Ca}^{2+}$ dynamics and antioxidant status. Free Radic Biol Med 40: 1592-1602, 2006.

KINOSHITA I, ITOH K, NISHIDA-NAKAI M, HIROTA H, OTSUJI S, SHIBATA N: Antiarrhythmic effects of eicosapentaenoic acid during myocardial infarction - enhanced cardiac microsomal $\left(\mathrm{Ca}^{2+}-\mathrm{Mg}^{2+}\right)$-ATPase activity. Jpn Circ J 58: 903-912, 1994.

KOSTIN S, DAMMER S, HEIN S: Connexin 43 expression and distribution in compensated and decompensated cardiac hypetrophy in patients with aortic stenosis. Cardiovasc Res 62: 426- 436, 2004.

KOYAMA T, XIE Z, GAO M, SUZUKI J, BATRA S: Adaptive changes in the capillary network in the left ventricle of rat heart. Jpn J Physiol 48: 229-241, 1998.

LAMBEIR AM, DURINX C, SCHARPE S, DE MEESTER I: Dipeptidyl-peptidase IV from bench to bedside: an update on structural properties, functions, and clinical aspects of the enzyme DPP IV. Crit Rev Clin Lab Sci 40: 209-294, 2003.

LEAF A, WEBER PC: Cardiovascular effects of N-3 fatty acids. $N$ Engl J Med 318: 549-557, 1988.

LEAF A, XIAO YF, KANG JX, BILLMAN GE: Prevention of sudden cardiac death by n-3 polyunsaturated fatty acids. Pharmacol Ther 98: 355-377, 2003.

LEE KW, LIP GYH: The role of omega-3 fatty acids in the secondary prevention of cardiovascular disease. $Q J$ Med 96: 465-480, 2003.

LEIFERT WR, DORIAN CL, JAHANGIRI A, MCMURCHIE EJ: Dietary fish oil prevents asynchronous contractility and alters $\mathrm{Ca}^{2+}$ handling in adult rat cardiomyocytes. J Nutr Biochem 12: 365-376, 2001.

LENDECKEL U, ARNDT M, WRENGER S, NEPPLE K, HUTH CH, ANSORGE S, KLEIN HU, GOETTE A: Expression and activity of ectopeptidases in fibrillating human atria. J Moll Cell Cardiol 33: 1273-1281, 2001.

LOJDA Z: Studies on dipeptidyl (amino) peptidase IV. Histochemistry 59: 153-166, 1979.

LOJDA Z, CEJKOVÁ J, BOLKOVÁ A, HAVRÁNKOVÁ E: Uneven distribution of alkaline phosphatase in individual layers of rabbit and ox cornea. Histochemical and biochemical study. Histochemistry 49: 237-243, 1976. 
MAZGALEV TN: Drugs, ablation, denervation and now fish oil: the global war on AF. $J$ Cardiovasc Electrophysiol 16: 1195-1199, 2005.

MOZAFFARIAN D, PRINEAS RJ, STEIN PK, SISKOVICK DS: Dietary fish and n-3 fatty acid intake and cardiac electrocardiographic parameters in human. J Amr Coll Cardiol 48: 478-484, 2006.

REIFFEL JA, MCDONALD A: Antiarrhytmic effects of omega-3 fatty acids. Am J Cardiol 98: 50-60, 2006.

SACKS FM, KATAN M: Randomized clinical trials on the effects of dietary fat and carbohydrate on plasma lipoproteins and cardiovascular disease. Am J Med 113 (9B): 13S-24S, 2002.

SAFFITZ J, SCHUESSLER RB, YAMADA KA: Mechanisms of remodelling of gap junction distribution and the development of anatomic substrates of arrhythmias. Cardiovasc Res 42: 309-317, 1999.

SISKOVICK DS, LEMAITRE RN, MOZAFFARIAN D: A diet-heart hypothesis with clinical implications: n-3 polyunsaturated fatty acids, myocardial vulnerability and sudden death. Circulation 107: 2632-2634, 2003.

SPACH MS, HEIDLAGE JF: The stochastic nature of cardiac propagation at a microscopic level. An electrical description of myocardial architecture and its application to conduction. Circ Res 76: 366-380, 1995.

TAMURA T, SAID S, GERDES M: Gender-related differencers in myocyte remodeling in progression to heart failure. Hypertension 33: 676-680, 1999.

TEUNISSEN BEJ, JONGSMA HJ, BIERHUIZEN MFA: Regulation of myocardial connexins during hypertrophic remodelling. Eur Heart J 25: 1979-1989, 2004.

TRIBULOVÁ N, OKRUHLICOVÁ L, NOVÁKOVÁ S, PANCZA D, BERNÁTOVÁ I, PECHÁŇNOVÁ O, WEISMANN P, MANOACH M, SEKI S, MOCHIZUKI S: Hypertension-related intermyocyte junction remodelling is associated with a higher incidence of low- $\mathrm{K}^{+}$-induced lethal arrhythmias in isolated rat heart. Exp Physiol 87: 195-205, 2002a.

TRIBULOVÁ N, OKRUHLICOVÁ L', VARON D, MANOACH M, PECHANOVÁ O, BERNÁTOVÁ I, WEISMANN P, BARANČÍK M, STYK J, SLEZÁK J: Structural substrates involved in the development of severe arrhythmias in hypertensive rat and aged guinea pig hearts. In: Cardiac Remodelling and Failure. SINGAL P, DIXON I, KIRSCHENBAUM L, DHALLA NS (eds), Kluwer Academic Publishers, Boston, 2002b, pp 377398.

TRIBULOVÁ N, OKRUHLICOVÁ L, IMANAGA I, HIROSAWA N, OGAWA K, WEISMANN P: Factors involved in the susceptibility of spontaneously hypertensive rats to low $\mathrm{K}^{+}$-induced arrhytmias. Gen Physiol Biophys 22: 369-382, 2003.

TRIBULOVÁ N, KNEZL V, FIALOVÁ M, DLUGOŠOVÁ K, OKRUHLICOVÁ L: Fish oil likewise atorvastatin decreases susceptibility of hypertriglyceridemic rat heart to ventricular fibrillation. Eur Heart J 28: 29, 2007.

VON SCHACKY C, HARRIS WS: Cardiovascular benefits of omega-3 fatty acids. Cardiovasc Res 73: 310-315, 2007.

VLKOVIČOVÁ J, JAVORKOVÁ V, PECHÁŇOVÁ O, VRBJAR N: Gender difference in functional properties of $\mathrm{Na}, \mathrm{K}-\mathrm{ATPase}$ in the heart of spontaneously hypertensive rats. Life Sci 76: 971-982, 2005.

ZICHA L, PECHÁŇOVÁ O, ČAČÁNYIOVÁ S, CEBOVÁ M, KRISTEK F, TŐRŐK J, ŠIMKO F, DOBEŠOVÁ Z, KUNEŠ J: Hereditary hypertriglyceridemic rat: a suitable model of cardiovascular disease and metabolic syndrome? Physiol Res 55 (Suppl 1): S49-S63, 2006. 